\title{
Histological examinations of the in vivo biocompatibility of oxycellulose implanted into rat skeletal muscle
}

\author{
Christiane Kunert-Keil ${ }^{1, C, D}$, Isabel Narath ${ }^{1, B}$, Jakub Hadzik2, ${ }^{2, D}$, Tomasz Gedrange ${ }^{1, A}$, Tomasz Gredes ${ }^{1, E}$, Marzena Dominiak ${ }^{2, F}$ \\ ${ }^{1}$ Department of Orthodontics, Carl Gustav Carus Campus, Technische Universität Dresden, Germany \\ 2 Department of Dental Surgery, Faculty of Dentistry, Wroclaw Medical University, Poland \\ A - research concept and design; $B$ - collection and/or assembly of data; $C$ - data analysis and interpretation; \\ $D$ - writing the article; $E$ - critical revision of the article; $F$ - final approval of the article
}

\begin{abstract}
Address for correspondence
Christiane Kunert-Keil

E-mail: christiane.kunert-keil@uniklinikum-dresden.de

Funding sources

None declared

Conflict of interest

None declared

\section{Acknowledgements}

We would like to thank Diana Jünger and Michaela Krause for their excellent technical assistance and Dr. Matthias Meinhardt (Department of Pathology, Carl Gustav Carus Campus, Technische Universität Dresden, Germany) for the assessment and analysis of the histological specimens.
\end{abstract}

Received on March 24, 2017

Reviewed on April 17, 2017

Accepted on January 22, 2018

Published online on August 3, 2018

\begin{abstract}
Background. Recently it was shown that oxycellulose suppressed bone regeneration led to an accumulation of connective tissue as well as foam cells in bone defects.

Objectives. Since oxycellulose can be used as a hemostatic agent in general and dental surgery, the aim of the study was to examine muscle tissue response to implanted oxidized cellulose.

Material and methods. RESO-Cel| ${ }^{\circledast}$ (Resorba Wundversorgung GmbH, Nuremberg, Germany) standard was implanted in the latissimus dorsi of 20 rats; subsequently, 12 samples were processed for histological evaluation after 4 and 8 weeks. The remaining 8 samples were processed for mRNA expression analyses of gene-encoding growth factors and collagens using quantitative reverse transcription polymerase chain reaction (RT-qPCR).
\end{abstract}

Results. Muscle tissue exposed to oxycellulose showed elevated mRNA levels of COLTA1 compared to untreated muscle tissue. The histological analysis revealed that no undegraded oxycellulose was detectable after as little as 4 weeks. Furthermore, a strong accumulation of CD68-positive foam cells was found in the treated area.

Conclusions. In conclusion, the study has shown that oxidized cellulose can cause an inflammatory response after this material is implanted in skeletal muscle. Therefore, it is not recommended to leave this material in the body over a long period. However, it could be used as auxiliary material in the treatment of periodontal defects.

Key words: skeletal muscle, implantation, qPCR, oxidized cellulose, histiocytic reaction

Cite as

Kunert-Keil C, Narath I, Hadzik J, Gedrange T, Gredes T, Dominiak M. Histological examinations of the in vivo biocompatibility of oxycellulose implanted into rat skeletal muscle. Adv Clin Exp Med. 2019;28(5):593-599. doi:10.17219/acem/83695

DOI

10.17219/acem/83695

Copyright

Copyright by Author(s)

This is an article distributed under the terms of the

Creative Commons Attribution Non-Commercial License

(http://creativecommons.org/licenses/by-nc-nd/4.0/) 


\section{Introduction}

One of the most common tissues for transplantation worldwide is bone. In the fields of orthopedics, neurosurgery and dentistry, bone grafts are used in order to reconstruct bone defects and stimulate bone healing after trauma and bone loss. ${ }^{1,2}$

There are several methods of bone transplantation; they include the use of autologous, allogeneic and xenogeneic bone tissues, as well as synthetic bone substitutes. Autologous bone is harvested from the patient's own body, while allografts are obtained from a bone bank. Xenogeneic bone, on the other hand, originates from other species. Synthetic variants can be created from ceramics, coralline hydroxyapatite, bioactive glasses, glass ionomers, and biological/synthetic composite grafts. ${ }^{1-3}$ The use of synthetic bioactive bone substitute materials is of keen interest in modern dentistry as an alternative to autogenous bone grafts.

To date, diverse types of biomaterials for bone regeneration have been used, e.g., non-mineral and mineral-based materials, with and without natural or artificial polymer. ${ }^{4,5}$ Heretofore, hyaluronic acid (HA)-based biomaterials, such as Geistlich Bio-Oss ${ }^{\circledR}$ (Geistlich Pharma AG, Wolhusen, Switzerland) or NanoBone ${ }^{\circledR}$ (Artoss Inc., Foley, USA), were the most abundant materials used in modern bone substitution. Calcium phosphate cements, such as Cerasorb ${ }^{\circledR}$ (Curasan AG, Frankfurt am Main, Germany) or Straumann Bone Ceramic ${ }^{\circledR}$ (Straumann Holding AG, Basel, Switzerland), currently play a secondary role in dentistry. ${ }^{2}$

It is well known that plants and animals naturally produce a variety of polymers which can serve as a solid source for biomaterials, such as collagen, silk or cellulose., ${ }^{2,6}$ The use of vegetable fibers in polymeric composites, in particular bast fibers from flax, hemp or jute, has been reported in many studies. ${ }^{7-10}$ Composites enhanced with natural fibers have been used in medicine as artificial scaffolds for tissues, drug-release systems, cardiovascular patches, or nerve cuffs. ${ }^{11,12}$ Recently it was shown that wound treatment with flax dressings effectively reduced wound exudates and fibrin levels, and increased new granulation. ${ }^{13}$ Furthermore, it has been demonstrated that cellulose fibers isolated from flax have good in vitro and in vivo biocompatibility and support bone regeneration. ${ }^{7-9}$ However, flax composites are of limited use because, although cellulose is hydrophilic, it is insoluble in water as well as most organic solvents, and is not biodegradable. ${ }^{10}$

Oxidized cellulose is a water-insoluble derivative of cellulose and it is one of the most important biocompatible and bioresorbable polymers. It can be produced after oxidation of highly pure cellulose in many different forms, such as powder, textile, paper, or fibers. ${ }^{14}$ Depending on the amount applied, oxycellulose can be absorbable. ${ }^{15,16}$ It has recently been shown that bone defects treated with oxidized cellulose were completely filled with connective tissue with embedded foam cells and that natural bone regeneration was suppressed. ${ }^{17}$ Contrary to these findings, oxidized cellulose has been long used as a hemostatic agent in general, oncoplastic breast and dental surgery. ${ }^{14-16,18-23}$

Tissue response to biomaterials depends on a variety of factors, including the physico-chemical properties of the implant, its biodegradability/bioresorbability, as well as the site of implantation. ${ }^{24-26}$ Due to the fact that oxidized cellulose could also be applicable for short-term treatment of bleeding or periodontal defects in dentistry, the aim of this study was to evaluate the absorbability and biocompatibility of the oxycellulose material RESO-Cell ${ }^{\circledR}$ standard (Resorba Wundversorgung GmbH, Nuremberg, Germany) by implanting it in rat muscle tissue. In addition, the specific tissue response to the implanted oxycellulose has been characterized.

\section{Material and methods}

\section{Test material}

Reso-Cell ${ }^{\circledR}$ standard is a resorbable hemostat made from oxidized cellulose. It is used in the form of gauze strips produced from natural cellulose derived from cotton.

\section{Experimental design and surgical procedure}

Twenty adult Lewis 1 A rats of both sexes (3 months old, body weight 250-350 g) were used. All the surgical and experimental procedures were approved by the Animal Welfare Committee of the State Government of MecklenburgWestern Pomerania (LALLF M-V/TSD/7221.3-1.1-033/11). Each rat was anesthetized with an intraperitoneal injection of ketamine (10\%; CEVA Tiergesundheit, Düsseldorf, Germany) and rompun (2\%; Bayer HealthCare, Leverkusen, Germany) and a skin incision was made on the back of the lattisimus dorsi muscle as described previously.,27 After exposition and transection of the fascia, the defect was covered with oxycellulose $(1 \times 1 \mathrm{~cm})$ and then subsequently closed with wound clips (Fig. 1). Five rats undergoing surgical procedures without any material insertion served as negative controls.

The rats were sacrificed after $4(n=14)$ or 8 weeks $(n=6)$ and the inserted material with the surrounding tissue of the latissimus dorsi muscle was harvested. The samples were processed for gene expression analysis $(n=9)$ and histological examination $(\mathrm{n}=11)$.

For the molecular-biological examinations, the samples were shock-frozen in liquid nitrogen and stored at $-80^{\circ} \mathrm{C}$. For the histological examination, the samples were placed in $4 \%$ formalin in phosphate-buffered saline (PBS) for 1 week at room temperature, then routinely dehydrated in a series of increasing concentrations of ethanol $(50 \%$, $70 \%, 80 \%, 90 \%, 96 \%$, and $100 \%$ ) or xylol for $12 \mathrm{~h}$, and finally embedded in paraffin. 

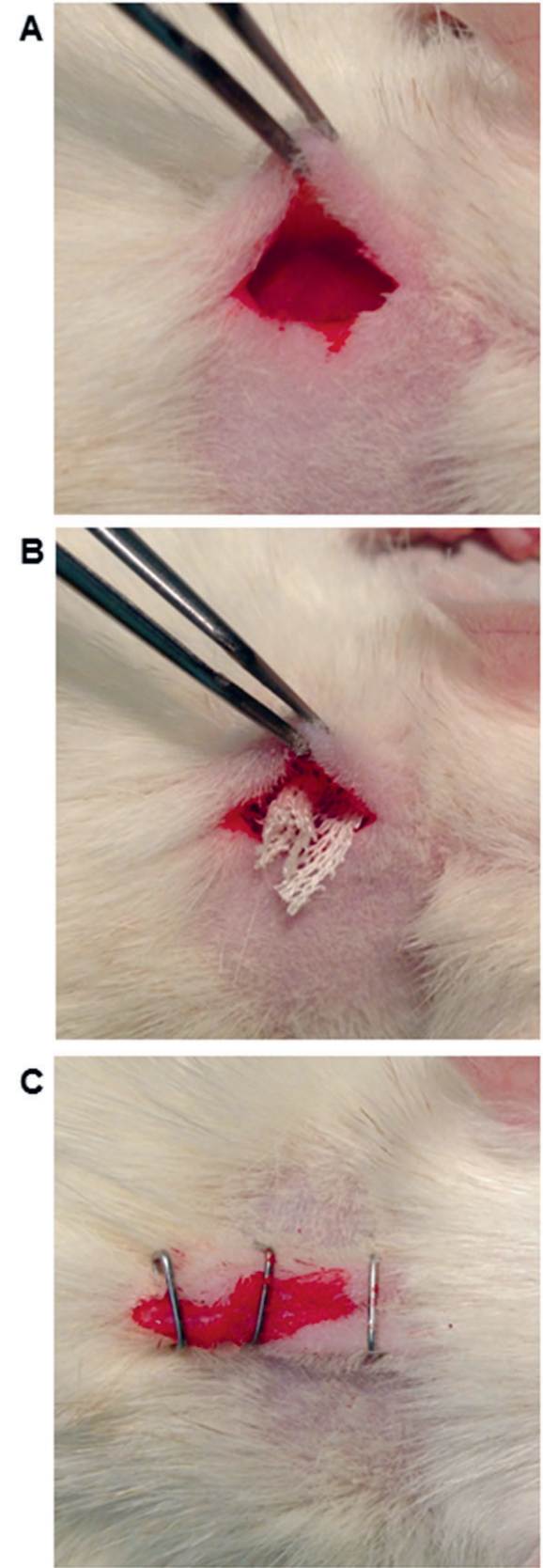

Fig. 1. Surgical approach: A - skin incision above the latissimus dorsi; B - insertion of the oxidized cellulose; $C$ - wound closure using skin staples

\section{Histological processing}

The paraffin blocks were trimmed in serial longitudinal sections of about $3 \mu \mathrm{m}$ using a microtome (Leica RM 2155; Leica Microsystems GmbH, Wetzlar, Germany). Some of the sections were then stained with hematoxylin/eosin
$(\mathrm{H} \& \mathrm{E})$ to assess the general overview of the tissue structure. Some sections were also immunostained against CD68 antibody, a marker for various cells of the macrophage lineage, including monocytes, histiocytes, giant cells, Kupffer cells, and osteoclasts; or against CD45, an antibody which distinguishes leucocytes/lymphocytes from nonhematopoietic cells.

For immunohistological (IHC) staining, the sections were first deparaffinized, rehydrated, rinsed for $10 \mathrm{~min}$ in tris-buffered saline (TBS) and incubated in citrate buffer $\mathrm{pH} 6.0$ in a water bath at $95-99^{\circ} \mathrm{C}$ for $40 \mathrm{~min}$. After cooling down the slides for $20 \mathrm{~min}$ at room temperature, the endogenous peroxidase was blocked with $0.3 \% \mathrm{H}_{2} \mathrm{O}_{2}$ in darkness. Following further rinsing, the sections were incubated with the primary antibody (Table 1) in a humid chamber. The staining was performed following the instructions for the EnVision+ System-HRP (DAKO, Glostrup, Denmark), counter-stained with Mayer's acid hemalum and then cover-slipped. For negative controls, the primary antibody was replaced by PBS.

\section{Quantitative reverse transcription polymerase chain reaction}

Homogenization of the muscle samples and total RNA isolation were performed using TRIzol and QIAzol lysis reagents (Qiagen Inc., Hilden, Germany) and the RNeasy ${ }^{\mathbb{R}}$ Lipid Kit (Qiagen) according to manufacturer's instructions. Quantitative reverse transcription polymerase chain reaction (RT-qPCR) for cDNA synthesis was done in the Thermocycler TOptical Real-Time PCR (Analytik Jena AG, Jena, Germany) using 200 ng RNA and innuSCRIPT Reverse Transcriptase, innuNucleotide Mix and Random primer (Analytik Jena AG).

The following genes were quantified: collagen type 1 and type 2 (COL1A1 and COL2A1); insulin-like growth factor $(I G F) 1$ and $I G F 2$; vascular endothelial growth factor $(V E G F)$; and myostatin $(M S T N)$, a negative regulator of muscle growth. The quantification of the expression of different rat genes were performed as described previously by using the master mix contained in the innuMix qPCR Master Mix Probe (Analytik Jena AG), $\times 10$ specific probes and primers (IGF1: Rn 00710306_m1; IGF2: Rn 00580426_m1; VEGF: Rn 01511602_m1; MSTN: Rn 00569683_m1; COL1A1: Rn 01463848_m1; COL2A1: Rn 00563954_m1; Eukaryotic 18S rRNA Endogenous Control: 4310893E; PE (Applied Biosystems, Weiterstadt, Germany) and RNase free water. ${ }^{7,27}$

Table 1. Details and incubation protocols of the antibodies used

\begin{tabular}{|l|c|c|c|}
\multicolumn{1}{|c|}{ Antibody } & Isotype & Producer & Incubation protocol \\
\hline CD45 & $\begin{array}{c}\text { rat } \\
\text { monoclonal, clone 30-F11 }\end{array}$ & $\begin{array}{c}\text { BD Bioscience } \\
\text { (Heidelberg, Germany) }\end{array}$ & $1: 50$, overnight, $4^{\circ} \mathrm{C}$ \\
\hline mouse & $\begin{array}{c}\text { Abcam } \\
\text { monoclonal }\end{array}$ & $1: 150$, overnight, $4^{\circ} \mathrm{C}$ \\
\hline
\end{tabular}




\section{Statistical analysis}

All the statistical analyses used the paired t-test and were performed using SigmaStat 3.5 software (Systat Software, Inc., San Jose, USA). Data is given as means \pm standard error of the mean (SEM). The p-value $<0.05$ was considered statistically significant.

\section{Results}

All the animals survived the procedure without major complications, such as allergic reactions, abscesses or infections, and postoperative healing was smooth.

\section{Degradation of oxycellulose in skeletal muscles: \\ the results of histiocytic infiltration}

In the histological sections after both 4 and 8 weeks, there were no signs of intact oxycellulose in the muscle tissues. Above the muscle tissue, a strong collection of round basophil cells was visible, which are normally not present in this area (Fig. 2A). On closer inspection, this cell collection could be identified as a marked resorptive histiocytic inflammation with an accumulation of foam cells. There were some histiocytes embedded in connective tissue that showed a foamy inside - probably an indication of captured oxycellulose particles. Furthermore, no giant cells, lymphocytes or encapsulation of the material were observed (Fig. 2,3). The area enriched in the rounded cells showed collagen accumulation (Fig. 2A). The accumulated cells were CD68-positive and thus of monocyte/macrophage origin (Fig. 4A). Nontreated control rats showed a slight positive reaction for CD68 in the epimysium (Fig. 4C).

\section{Quantitative reverse transcription polymerase chain reaction}

Four weeks after oxycellulose insertion, the animals were sacrificed and 2 muscle sections were prepared: 1 . treated muscle tissue and 2. untreated muscle tissue. Both samples from each rat were used for molecular-biological analyses and the intra-individual gene expression of collagens and
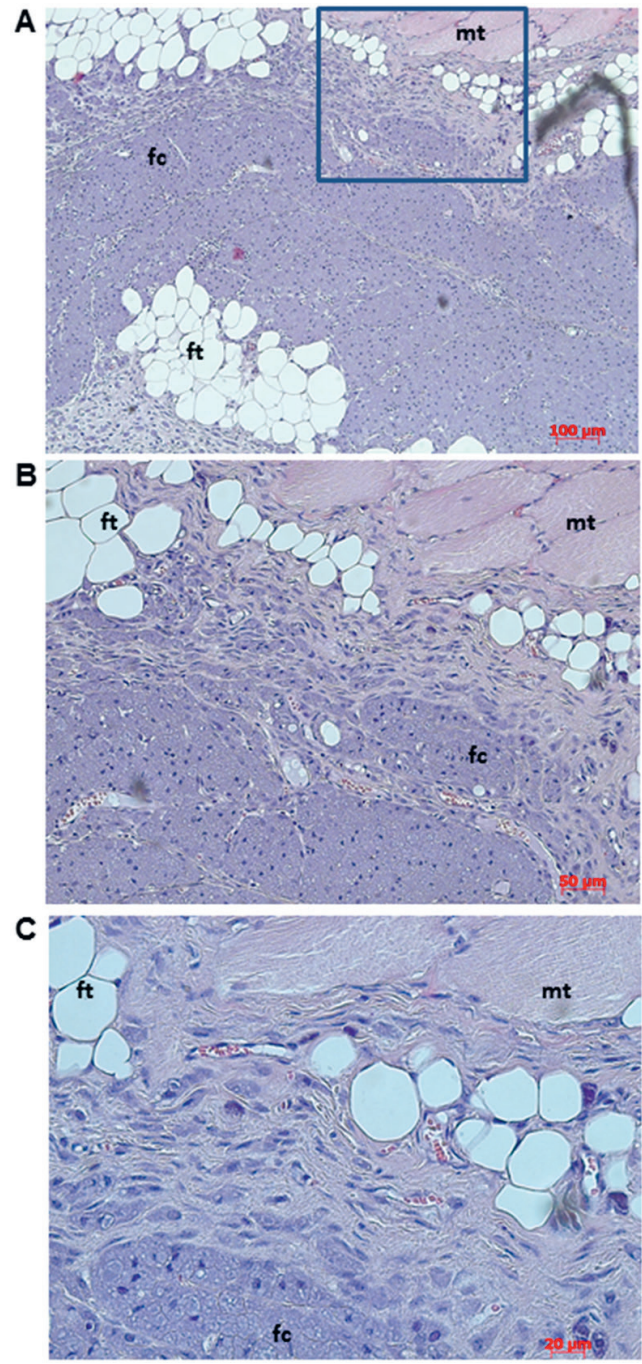

Fig. 2. Hematoxylin/eosin (H\&E) staining of muscle tissue cross-section embedded in paraffin 4 weeks after the insertion of oxidized cellulose: A - overview image, magnification $\times 100$; the blue frame marks the area of the enlarged photographs as shown in B - magnification $\times 200$ and C - magnification $\times 400$

fc - foam cells; $m$ t - muscle tissue; ft - fatty tissue.

growth factors were detected (Table 1). In oxycellulosetreated muscle tissue, 1.9 times higher mRNA levels of $\mathrm{CO}$ $L 1 A 1$ were found. None of the other genes tested showed any difference between muscle tissue from oxycellulosetreated and untreated rats (Table 2).

Table 2. Gene specific transcription levels in rat muscle tissue samples. The mRNA levels are given in relation to those of $18 \mathrm{~S}$ rRNA. Means \pm standard error of the mean (SEM) are given in all cases for $n=8$ samples. The $p$-values indicate statistically significant differences between oxycellulose-treated muscle tissue and untreated tissue from the same rat; paired t-test

\begin{tabular}{|l|c|c|c|}
\multicolumn{1}{|c|}{ Gene } & Treated muscle & Untreated muscle \\
\hline COLIA1 & $0.32 \pm 0.092$ & $0.62 \pm 0.15$ \\
\hline COL2A1 & $0.0057 \pm 0.0035$ & $0.018 \pm 0.0069$ \\
\hline IGF1 & $0.014 \pm 0.0028$ & $0.018 \pm 0.0028$ \\
\hline IGF2 & $0.013 \pm 0.003$ & 0.008 \\
\hline VEGFA & $0.016 \pm 0.0015$ & $0.013 \pm 0.0039$ \\
\hline MSTN & $0.021 \pm 0.0074$ & 0.0033 \\
\hline
\end{tabular}


A

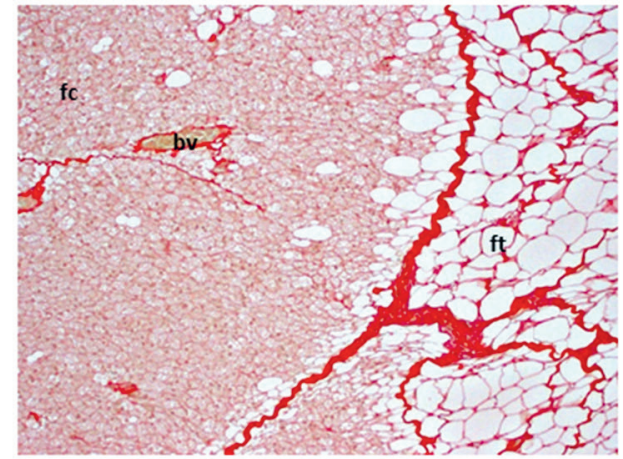

B

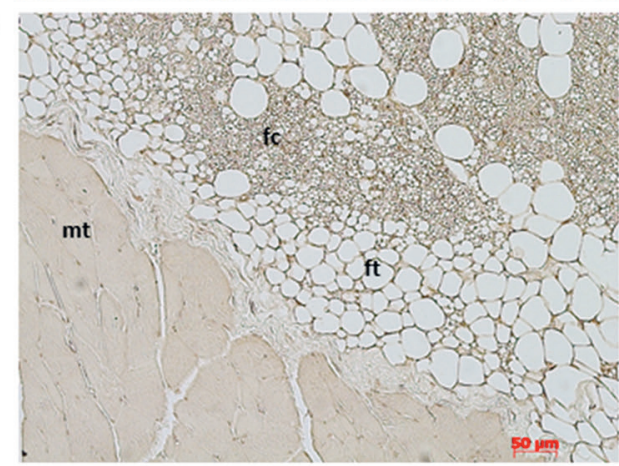

C

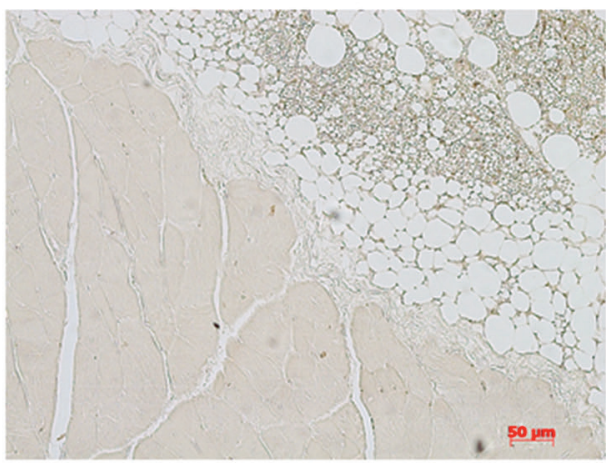

Fig. 3. A - Sirius Red staining and B - detection of CD45 antibody in muscle tissue cross-section embedded in paraffin 4 weeks after the insertion of oxidized cellulose; C - control staining with phosphatebuffered saline (PBS) instead of the primary antibody. Magnification ×200

$\mathrm{fc}$ - foam cells; $\mathrm{mt}$ - muscle tissue; $\mathrm{ft}$ - fatty tissue: bv - blood vessel.

\section{Discussion}

The use of plant fibers for the production of wound covering materials is becoming an important area of science. Effective wound closure, reduced treatment times and reductions in post-traumatic infection can be achieved by imbedding drugs in the fiber materials. ${ }^{28}$ It was recently shown that treatment with flax dressing products from genetically engineered flax plants able to synthesize antioxidative compounds reduced wound exudates, wound size and fibrin levels, and increased the level of new granulation in patients with chronic venous ulceration..$^{13}$ Another genetically modified flax plant was able to produce polyhydroxybutyrate (PHB).$^{29}$ Composites from these plants have demonstrated good in vitro and in vivo biocompatibility. ${ }^{7-9}$ A problem with the use of plant fibers is the fact that they are not biodegradable and cannot be absorbed, since the
A

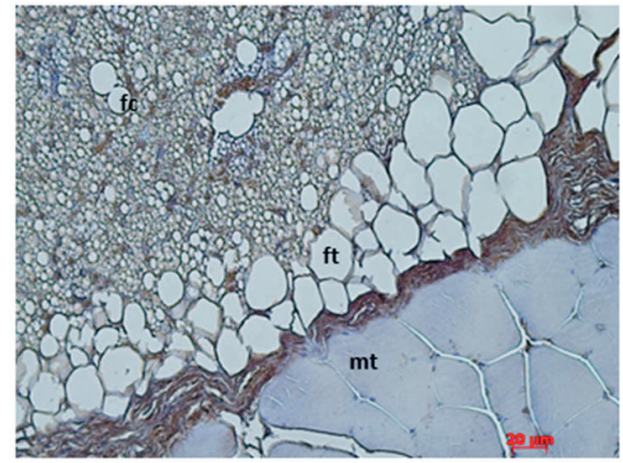

B

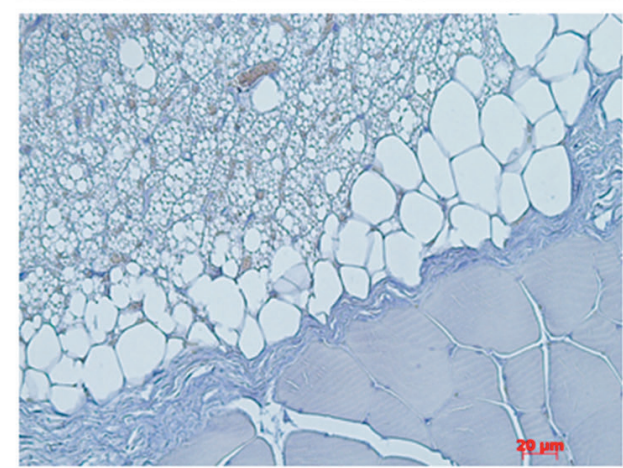

C

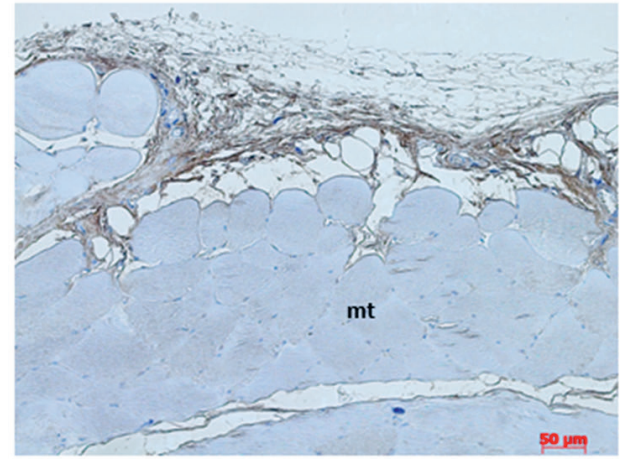

Fig. 4. Detection of CD68 antibody in muscle tissue cross-section embedded in paraffin from $(A+B)$ oxidized cellulose-treated rats and $C$ - untreated rats; $B$ - control staining with phosphate-buffered saline (PBS) instead of the primary antibody. Magnification $\times 400(A+B)$ and $\times 200(C)$

fc - foam cells; $m$ t - muscle tissue; ft - fatty tissue.

main component of the fibers is the natural polymer cellulose. ${ }^{30}$ This problem can be circumvented by oxidizing the cellulose.

Oxidized cellulose was first introduced in 1943 and was developed by controlled oxidation of cellulose. ${ }^{31}$ This material is widely used to control intraoperative diffuse capillary, venous and small-arterial bleeding in general surgery and breast-conserving surgery. ${ }^{14-16,18,19,21-23}$ Furthermore, tissue regeneration after surgical exposure of periodontal defects has been shown when using oxidized cellulose meshes. ${ }^{20,32}$ Due to the fact that oxidized cellulose is bioabsorbable within 7-14 days, this material is often left in the surgical bed. ${ }^{33}$ It is advantageous that oxycellulose has definite and potent antipathogenic effects against a variety of organisms as well as an ability to mediate blood-platelet aggregation, deposition and activation. ${ }^{34-36}$ 
Meanwhile, there have been many other reports about the histopathologic effects of hemostatic reagents in animals and humans..$^{33,37-39}$ Rather mild side effects have been described. Oxidized cellulose applied on the epidural region of laminectomy sites in rats caused chronic inflammation, moderate or severe fibrosis and mild or moderate increased vascularity in some animals. ${ }^{39}$ Similar results were described in an experimental study on the use of oxycellulose as filler in oncoplastic breast cancer. ${ }^{22}$ An increase in connective tissue was confirmed by the molecular biological studies in the present work: we found that COL1A1 mRNA expression was significantly increased in oxycellulose-treated muscle tissue compared to the untreated animals. The histological results of the study presented here showed more serious side effects: we found a persistent strong resorptive histiocytic reaction in the implantation bed of oxidized cellulose. Resorptive histiocytic inflammation is a reaction of macrophages/foam cells, which record the material in the cells. In contrast, both giant cells and lymphocytes were missing. Thus, our results are consistent with those of previous studies. ${ }^{39}$

It is well-known that oxidized cellulose decreases the $\mathrm{pH}$ value of the surrounding tissue. The lowering of the $\mathrm{pH}$ is the reason for the antimicrobial effect against pathogenic organisms. ${ }^{34,35}$ However, Tomizawa showed that acidic $\mathrm{pH}$ also increases inflammation of the surrounding tissue and delays wound healing. ${ }^{40}$ Recently, it was reported that the use of oxidized cellulose could cause intra-abdominal foreign-body granuloma, a more serious side effect, which is indistinguishable at first glance from a tumor. ${ }^{33,37,38}$

As early as 1943 it was shown that the biodegradation of oxidized cellulose depends on different factors, such as the quantity of implanted material and environmental conditions. ${ }^{31}$ It should be noted that the size of the implanted oxycellulose used in our study $\left(1 \mathrm{~cm}^{2}\right)$ was very large in comparison with the implantation site. This, among other things, may have triggered the strong inflammatory reaction. Indeed, we observed clear infiltration of mononuclear cells in the muscle tissue in the area of the implanted oxycellulose. However, no oxycellulose could be observed 4 weeks after its implantation. This implies that the filling material was absorbed by the activity of monocytes/ macrophages, identified by the presence of the common CD68 antigen, which extensively infiltrated the treated muscle tissue.

The implantation site plays also an important role in the biodegradability of oxycellulose. ${ }^{31}$ It was recently shown that the use of oxidized cellulose was characterized by diffuse fibrosis and neovascularization within the oxycellulose construct at postoperative week 20, without any inflammatory effects or encapsulation. Furthermore, macrophages were predominantly found 10 weeks after surgery, whereas fibroblasts dominate at postoperative week $20 .{ }^{22}$ These results indicate that in the case of experimental breast-conserving surgery the oxycellulose was still detectable even after 30 weeks. In the current study, no intact cellulose fibers were found 4 and 8 weeks after insertion of the oxycellulose strips on the latissimus dorsi. A previous study reported a similar observation in the skulls of rats: no residual fibers of oxycellulose could be detected after 8 weeks. In that earlier study it was demonstrated that insertion of oxidized cellulose in bone defects resulted in decreased bone healing. The surgically created bone defects were completely filled with connective tissue with embedded foam cells. Furthermore, bone resorption processes seemed to be activated, since residual bone was resorbed. ${ }^{17}$ The biggest difference between our new study and a study by Franceschini et al. was that in that study, no accumulation of absorbed oxycellulose could be detected in the breast tissue of the rats. ${ }^{22}$ This could be due to the nature of the material; in our study strongly woven oxycellulose fibers were used (data not shown).

\section{Conclusions}

In conclusion, the study has shown that oxidized cellulose can cause an inflammatory response after this material is implanted in skeletal muscle tissue. Therefore, it is not recommended to leave this material in the body over a long period. However, this material could be used as an auxiliary material in the treatment of periodontal defects.

\section{References}

1. Giannoudis PV, Dinopoulos H, Tsiridis E. Bone substitutes: An update. Injury. 2005;36:(Suppl 3):S20-S27.

2. Kunert-Keil C, Gredes T, Gedrange T. Biomaterials applicable for alveolar sockets preservation: In vivo and in vitro studies. In: Turkyilmaz, I, ed(s). Implant Dentistry - The Most Promising Discipline of Dentistry. London, UK: InTech; 2011. Published on October 3, 2011. doi: $10.5772 / 18459$

3. Burg KJ, Porter S, Kellam JF. Biomaterial developments for bone tissue engineering. Biomaterials. 2000;21(33):2347-2359.

4. Coombes AG, Meikle MC. Resorbable synthetic polymers as replacements for bone graft. Clin Mater. 1994;17(1):35-67.

5. Razak SA, Sharif N, Rahman W. Biodegradable polymers and their bone applications: A review. International Journal of Basic \& Applied Sciences. 2012;12(1):31-49.

6. Moire L, Rezzonico E, Poirier Y. Synthesis of novel biomaterials in plants. J Plant Physiol. 2003;160(7):831-839.

7. Gredes T, Kunert-Keil C, Dominiak M, Gedrange T, Wróbel-Kwiatkowska M, Szopa J. The influence of biocomposites containing genetically modified flax fibers on gene expression in rat skeletal muscle. Biomed Tech (Berl). 2010;55(6):323-329.

8. Gredes T, Wrobel-Kwiatkowska M, Dominiak M, Gedrange T, KunertKeil C. Osteogenic capacity of transgenic flax scaffolds. Biomed Tech (Berl). 2012;57(1):53-58.

9. Kunert-Keil C, Gredes T, Meyer A, Wróbel-Kwiatkowska M, DominiakM, Gedrange T. The survival and proliferation of fibroblasts on biocomposites containing genetically modified flax fibers: An in vitro study. Ann Anat. 2012;194(6):513-517.

10. Zini E, Scandola M. Green composites: An overview. Polym Compos. 2011:32(12):1905-1915.

11. Kraitzer A, Kloog Y, Zilberman M. Novel farnesylthiosalicylate (FTS)-eluting composite structures. Eur J Pharm Sci. 2009;37(3-4): 351-362.

12. van Dam JEG, van Vilsteren GET, Zomers FHA, et al. Increased application of domestically produced plant fibers in textile, pulp and paper production, and composite materials. Industrial Fiber Crops, European Commission Directorate-General XII. 1996. 
13. Skórkowska-Telichowska K, Zuk M, Kulma A, et al. New dressing materials derived from transgenic flax products to treat long-standing venous ulcers: A pilot study. Wound Repair Regen. 2010;18(2):168-179.

14. Bajerova M, Krejcova K, Rabiskova M, et al. Oxycellulose: Significant characteristics in relation to its pharmaceutical and medical application. Advances in Polymer Technology. 2009;28(3):199-208.

15. Bechstein WO, Strey C. Local and systemic hemostasis in surgery [in German]. Chirurg. 2007;78(2):95-96,98-100.

16. Schonauer C, Tessitore E, Barbagallo G, Albanese V, Moraci A. The use of local agents: Bone wax, gelatin, collagen, oxidized cellulose. Eur Spine J. 2004; 13(Suppl 1):S89-S96.

17. Kunert-Keil C, Hadzik J, Grewe I, et al. Osteogenic potential of oxycellulose: A molecular-biological and histological study in rats. J Cytol Histol. 2015;6:1-5.

18. Kollar P, Suchy P, Muselik J, Bajerová M, Havelka P, Sopuch T. Hemostatic effects of oxidized cellulose [in Czech]. Ceska Slov Farm. 2008; 57(1):11-16.

19. Levy ML, Amar AP. The use of oxidized regenerated cellulose in neurosurgical procedures. Surg Technol Int. 1998;7:467-471.

20. Pollack RP, Bouwsma OJ. Applications of oxidized regenerated cellulose in periodontal therapy: Part 1. Compendium. 1992;13(10):888, 890,892 passim.

21. Franceschini G, Visconti G, Masetti R. Oncoplastic breast surgery with oxidized regenerated cellulose: Appraisals based on five-year experience. Breast J. 2014;20(4):447-448.

22. Franceschini G, Visconti G, Sanchez AM, Di Leone A, Salgarello M, Masetti R. Oxidized regenerated cellulose in breast surgery: Experimental model. J Surg Res. 2015; 198(1):237-244.

23. Franceschini G, Visconti G, Terribile D, et al. The role of oxidized regenerate cellulose to prevent cosmetic defects in oncoplastic breast surgery. Eur Rev Med Pharmacol Sci. 2012;16(7):966-971.

24. Burugapalli K, Pandit A. Characterization of tissue response and in vivo degradation of cholecyst-derived extracellular matrix. Biomacromolecules. 2007;8(11):3439-3451.

25. Burugapalli K, Thapasimuttu A, Chan JC, et al. Scaffold with a natu ral mesh-like architecture: Isolation, structural, and in vitro characterization. Biomacromolecules. 2007;8(3):928-936.

26. Kunert-Keil C, Scholz F, Gedrange T, Gredes T. Comparative study of biphasic calcium phosphate with beta-tricalcium phosphate in rat cranial defects: A molecular-biological and histological study. Ann Anat. 2015;199:79-84.
27. Gredes T, Spassov A, Mai R, et al. Changes in insulin like growth factors, myostatin and vascular endothelial growth factor in rat musculus latissimus dorsi by poly-3-hydroxybutyrate implants. J Physiol Pharmacol. 2009;60(Suppl 3):77-81.

28. Moryganov AP, Galashina VN, Dymnikova NS, Danilov AR. Modification of flax fibres: From research to realization. Fibre Chemistry. 2008;40(3):234-240.

29. Szopa J, Wrobel-Kwiatkowska M, Kulma A, et al. Chemical composition and molecular structure of fibers from transgenic flax producing polyhydroxybutyrate, and mechanical properties and platelet aggregation of composite materials containing these fibers. Compos Sci Technol. 2009;69(14):2438-2446.

30. Maijala P, Makinen M, Galkin S, Fagerstedt K, Härkäsalmi T, Viikari L. Enzymatic modification of flaxseed fibers. J Agric Food Chem. 2012; 60(44):10903-10909.

31. Frantz VK. Absorbable cotton, paper and gauze: (oxidized cellulose). Ann Surg. 1943;118(1):116-126.

32. Galgut PN. Oxidized cellulose mesh. I. Biodegradable membrane in periodontal surgery. Biomaterials. 1990;11(8):561-564.

33. Tefik T, Sanli O, Oktar T, Yucel OB, Ozluk Y, Kilicaslanb I. Oxidized regenerated cellulose granuloma mimicking recurrent mass lesion after laparoscopic nephron sparing surgery. Int J Surg Case Rep. 2012; 3(6):227-230.

34. Spangler D, Rothenburger S, Nguyen K, Jampani H, Weiss S, Bhende S. In vitro antimicrobial activity of oxidized regenerated cellulose against antibiotic-resistant microorganisms. Surg Infect (Larchmt). 2003;4(3):255-262.

35. Wagner WR, Pachence JM, Ristich J, Johnson PC. Comparative in vitro analysis of topical hemostatic agents. J Surg Res. 1996;66(2):100-108.

36. Masova L, Rysava J, Krizova P, et al. Hemostyptic effect of oxidized cellulose on blood platelets. Sb Lek. 2003;104(2):231-236.

37. Altun I. An experimental study on histopathological effects of hemostatic agents used in spinal surgery. World Neurosurg. 2016;90:147-153.

38. Lemoy MJ, Schouten AC, Canfield DR. Granuloma due to oxidized regenerated cellulose in an aged rhesus macaque (Macaca mulatta). Comp Med. 2016;66(1):59-62.

39. Wang $\mathrm{H}$, Chen P. Surgicel ${ }^{\circledR}$ (oxidized regenerated cellulose) granuloma mimicking local recurrent gastrointestinal stromal tumor: A case report. Oncol Lett. 2013;5(5):1497-1500.

40. Tomizawa Y. Clinical benefits and risk analysis of topical hemostats: A review. J Artif Organs. 2005;8(3):137-142. 